\title{
O Produto Turístico All Inclusive na Ilha de Tenerife, Espanha: características, problematizações e desafios
}

\author{
The Tourism Product All Inclusive in Tenerife Island, Spain: \\ features, problematizations and challenges
}

\section{El Producto Turístico Todo Incluido en la Isla de Tenerife, España: características, retos y problematizaciones}

\author{
Christianne Luce Gomes ${ }^{1}$ \\ Joyce Kimarce do Carmo Pereira ${ }^{2}$
}

\section{Resumo}

Este artigo é fruto de uma pesquisa que objetivou compreender as características e influências da modalidade de viagem All Inclusive (Todo Incluido -TI) na ilha de Tenerife, na Espanha. A investigação foi guiada pelos questionamentos: Como esse produto se configura em Tenerife, e quem são os turistas que o consomem? De que maneira o TI é apreendido pelos turistas? Os turistas que adquirem o TI têm motivação para visitar outros atrativos turísticos da ilha? A metodologia baseou-se na pesquisa bibliográfica, documental e realização de entrevistas com turistas TI hospedados em dois hotéis da região, especialistas em Turismo e Hotelaria, e animadores de hotel. Os resultados evidenciaram que a principal motivação para adquirir o TI está relacionada ao preço acessível. Os depoentes alegaram disposição para consumir os produtos, benefícios e variedade de serviços ofertados no próprio empreendimento, o que acaba retendo os turistas dentro dos hotéis e inibindo visitas a outros atrativos. Quase todos os turistas entrevistados (20 dos 23) não tinham pretensão de sair do hotel para conhecer os demais atrativos da região para evitar gastos extras. Os entrevistados acreditam que o pacote proporciona tranquilidade, descanso, lazer, comodidade e liberdade. Foi possível verificar que o pacote TI é regido basicamente pelo poder privado, têm causado um grande impacto nos demais serviços, equipamentos e atrativos turísticos da região, está em constante crescimento e carece de regulamentação por meio de políticas públicas de turismo de caráter intersetorial a fim de minimizar os efeitos gerados pelo produto.

Palavras-chave: All Inclusive - Todo Incluido; Turistas; Viagem.

\begin{abstract}
This article is the result of a research that aimed to understand the characteristics and influences of travel mode All Inclusive (AI) on the island of Tenerife, Spain. The research was

\footnotetext{
1 Professora da Universidade Federal de Minas Gerais. Líder dos grupos de pesquisa OTIUM e LUCE: Ludicidade, Cultura e Educação da Universidade Federal de Minas Gerais (UFMG/CNPq). Belo Horizonte, Brasil. E-mail: chris@ufmg.br

${ }^{2}$ Mestranda em Estudos Interdisciplinares do Lazer pela Universidade Federal de Minas Gerais. Integrante do grupo de pesquisa História e Antropologia do Lazer da Universidade Federal de Minas Gerais (UFMG/CNPq). Belo Horizonte, Brasil. E-mail: joycekimarce@ hotmail.com
} 
guided by the following questions: How does this product is configured in Tenerife, and who are the tourists who consume it? How it is perceived by tourists? Tourists who purchase it have motivation to visit other tourist attractions in Tenerife? The methodology was based on the literature, documentary and interviews with it tourists staying in two hotels in the area, specialists in Tourism and Hospitality, and hotel workers. The results showed that the primary motivation for acquiring IT is related to affordability. Deponents alleged willingness to consume the products, benefits and variety of services offered in the project itself, which ultimately retaining tourists in the hotels, inhibiting visits to other attractions. Almost all respondents tourists (20 of 23) tourists had no intention of leaving the hotel to meet the other attractions of the region, to avoid extra expenses. For them the primary motivation for acquiring it refers to the affordable price. Respondents believe the package provides tranquility, rest, leisure, convenience and freedom. It was verified that the it package is governed primarily by the private sector, have caused a great impact on other services, equipment and tourist attractions of the region, is constantly growing and needs regulation by means of inter-sector tourism public policies minimize the effects generated by the product.

Keywords: All inclusive; Tourist; Travel.

\section{Resumen}

Este trabajo es el resultado de una investigación dirigida a la comprensión de las características e influencias del paquete Todo Incluido (TI) en la isla de Tenerife, España. La investigación se basó en las preguntas: ¿De qué manera este producto está configurado en Tenerife, y quiénes son los turistas que lo consumen? Cómo es percibida por los turistas? Los turistas que comprarlo tiene motivación para visitar otros servicios turísticos de la isla? La metodología se basa en la literatura, documentos y entrevistas con los turistas de TI alojados en dos hoteles en la zona, especialistas en Turismo y Hotelería, y trabajadores del hotel. Los resultados mostraron que la principal motivación para la compra del TI se relaciona con el precio bajo. Los deponentes tenían ganas de consumir los productos, los beneficios y la variedad de los servicios ofrecidos en el hotel, que por supuesto detiene a los turistas en los hoteles y disminuye las visitas a otros lugares de interés. Casi todos los turistas entrevistados (20 de 23) no tenían ninguna intención de dejar el hotel para conocer a los otros atractivos de la zona para evitar gastos extras. Los encuestados creen que el paquete proporciona la tranquilidad, el descanso, el ocio, la comodidad y la libertad. Se verificó que el paquete se rige principalmente por el sector privado, han causado un gran impacto en otros servicios, componentes y atracciones turísticas de la región, está en constante crecimiento y necesita de la regulación por medio de políticas de turismo intersectoriales a fin para minimizar los efectos generados por el producto.

Palabras clave: Todo Incluido; Los turistas; Viajes.

\section{Introdução: a pesquisa proposta e os conceitos que a fundamentam}

O turismo, cada vez mais, adquire relevância em vários contextos devido ao seu potencial econômico, mas, o enfoque social desse fenômeno também precisa ser difundido e valorizado.

Nesse sentido, Ignarra (1998) pontua que turismo é um fenômeno social, no qual as pessoas 
deslocam-se voluntariamente por um determinado período por diversos motivos, tais como recreação, descanso, cultura ou saúde. De acordo com o autor, esse deslocamento gera, fundamentalmente, inúmeras inter-relações de importância social, econômica e cultural. Similar a esse posicionamento, Funari e Pinsky (2003, p.7) acreditam que as movimentações turísticas implicam em duas premissas: o "contato humano e cultural" e as "trocas de experiências entre os viajantes e a população local' '.

Por isso, como lembra Santana (1997), o turismo é uma atividade complexa e dinamizada em estreita relação com a sociedade e suas nuances - comportamento, motivações, valores, história, tradições, crenças entre outros. Pode-se dizer, assim, que o turismo envolve:

[...] uma combinação complexa de inter-relacionamentos entre produção e serviços, em cuja composição integram-se uma prática social com base cultural, com herança histórica, a um meio ambiente diverso, cartografia natural, relações sociais de hospitalidade, troca de informações interculturais. O somatório desta dinâmica sociocultural gera um fenômeno, recheado de objetividade/subjetividade, consumido por milhões de pessoas, como síntese: o produto turístico. (MOESCH, 2000, p.7).

O "produto turístico" é um dos elementos cruciais para o desenvolvimento da atividade turística. Garcia (1998) pontua que o produto turístico é aquele que irá cobrir a "experiência de viagem" do consumidor em todo o seu conjunto de necessidades, desde a saída do indivíduo de seu ambiente domiciliar até o seu retorno. Segundo o autor, desde o momento da chegada ao destino, a principal motivação da viagem é o produto turístico. Ou seja, aquele escolhido e adquirido para ser consumido e desfrutado.

Como esclarecem Navarro e López (2011), o Todo Incluido (TI) - expressão espanhola que não é muito empregada em português, mas, em inglês, significa All inclusive (AI) - é um produto turístico, modalidade de viagem ou pacote turístico vendido previamente por um valor fixo. Ele contempla serviços de hospedagem, comida, bebida, atividades de lazer, animação e esportes, associado ao transporte aéreo e transfer in/out do aeroporto. Consiste, de modo geral, numa parceria firmada entre agências e operadoras de viagem, rede hoteleira e companhias aéreas denominadas Low Cost, que disponibilizam passagens de baixo custo, consideradas mais acessíveis.

De acordo com os autores, o fenômeno TI vem sendo implantado em destinos turísticos emergentes, geralmente denominados de "sol e praia", considerando três características: (a) destinação turística onde o desenvolvimento do lazer é praticamente inexistente ou insuficiente, (b) locais que apresentam momentos de crise econômica, instabilidades 
financeiras e problemas socioeconômicos, e (c) necessidades e motivação de uma demanda preconizando preços mais acessíveis, com pagamento prévio de todos os custos da viagem.

Assim, o TI é considerado como um fator contribuinte para o desenvolvimento do turismo, sendo mercadologicamente vantajoso para determinada localidade e empreendimentos que estejam na liderança. Pesquisas realizadas por Poon (1998); Issa e Jayawardena (2003) evidenciam que o produto vem logrando significativo êxito no Caribe, assim como no arquipélago de Canárias, na Espanha.

O arquipélago Canário contempla sete ilhas: La palma, El Hierro, La Gomera, Gran Canaria, FuerteVentura, Lanzarote e Tenerife. Essa última ilha forma parte da Espanha desde sua colonização em 1496, e é dividida em Tenerife Norte e Tenerife Sul. Apresenta, atualmente, 31 municípios e sua capital é Santa Cruz de Tenerife. É a maior ilha do arquipélago Canário tanto em extensão territorial (superfície de $2.035 \mathrm{~km}^{2}$ ), como em densidade demográfica (898.680 habitantes - censo de 2012 do Instituto Canario de Estadística (ISTAC). Vale ressaltar que nos últimos anos, o produto turístico TI vem sendo bastante difundido em Tenerife.

Considerando essa realidade, alguns questionamentos foram elaborados: Como se configura atualmente o TI nas Ilhas Canárias, especialmente em Tenerife? Quem são os turistas que consomem esse produto turístico? De que maneira o TI é apreendido pelos turistas de Tenerife? Os turistas que adquirem o TI têm motivação para visitar outros atrativos turísticos dessa ilha?

Em face dessas indagações, este artigo sintetiza os resultados de uma pesquisa que objetivou identificar e discutir as razões que propiciaram a implantação do produto Todo Incluido nas Ilhas Canárias, sobretudo em Tenerife; compreender como a prática TI é assimilada pelos turistas consumidores dessa modalidade e identificar seus possíveis impactos e influências nos demais atrativos da ilha.

\section{Metodologia}

Esta pesquisa de abordagem qualitativa compreendeu três estratégias: estudo bibliográfico, análise documental e realização de entrevistas estruturadas.

A pesquisa bibliográfica foi feita em livros, artigos e outras publicações relacionadas com as principais temáticas tratadas no estudo. Paralelamente, foi realizada uma pesquisa documental, que, de acordo com Santos (2000, p. 32), "é realizada em fontes como tabelas 
estatísticas, cartas, pareceres, fotografias, atas, relatórios, obras originais de qualquer natureza - pintura, escultura, desenho, etc".

A pesquisa documental contemplou, primeiramente, a Encuesta de Turismo Receptivo (Informe Situación turística de Tenerife Enero 2014; Presentación situación turística y perfil 2013, e Los turistas de Tenerife 2012), elaborado pela prefeitura Tenerife. Tais documentos contemplam informações sobre os serviços contratados pelos turistas tanto em origem quanto no destino, bem como o perfil dos visitantes e a situação turística da ilha. A pesquisa documental também considerou os dados estatísticos da aquisição de pacotes turísticos e o fluxo de visitantes em Tenerife dos anos de 2012 e 2013, fornecidos pelo Instituto Canario de Estadística (ISTAC). E por último, o IMPACTUR Canarias 2012 - elaborado pelo governo em parceria com a associação Exceltur -, com o objetivo de quantificar os efeitos diretos e indiretos gerados pela atividade turística.

Para enriquecer e aprofundar a investigação, foram feitas entrevistas estruturadas em duas hospedagens de Tenerife que oferecem o TI. A seleção dos turistas entrevistados seguiu dois critérios: (a) ser turista hospedado na modalidade TI e (b) estar hospedado por um período igual ou superior a uma semana, tempo este considerado suficiente para o turista ter realizado atividades turísticas externas ao estabelecimento hoteleiro, caso tivesse interesse. No primeiro hotel foram entrevistados 13 turistas e, no segundo, 10. Em seguida, foram entrevistados 2 especialistas em Turismo e Hotelaria que atuaram na gerência do ramo da hotelaria em Tenerife nos últimos 10 anos. Também foram entrevistados 2 animadores que trabalhavam nos hotéis pesquisados, totalizando assim, 27 pessoas.

Todos os entrevistados concordaram em participar da pesquisa voluntariamente, o que foi confirmado por meio da assinatura de um Termo de Consentimento Livre e Esclarecido (TCLE). As identidades dos entrevistados e dos hotéis foram mantidas em sigilo, como forma de preservar o seu anonimato. Para isso, cada entrevistado foi designado por uma sigla, conforme o grupo. Assim, os turistas foram designados pelas letras ETI; os especialistas em turismo e hotelaria EETH, e animadores, ETA.

Foi utilizado o critério de saturação para se chegar ao número final de entrevistas. "A saturação designa o momento em que o acréscimo de dados e informações em uma pesquisa não altera a compreensão do fenômeno estudado" (THIRY-CHERQUES, 2006, p. 21). Sendo 
assim, quando se chega à repetição das respostas e nenhuma outra nova informação é acrescentada, pode-se finalizar a coleta.

A sistematização e análise das informações coletadas baseou-se, portanto, na pesquisa bibliográfica, análise documental e entrevistas. Com essas diferentes estratégias metodológicas, buscou-se peculiaridades do produto turístico Todo Incluido de Tenerife. Desse modo, no próximo tópico pretende-se compreender melhor as características, influências e desafios dessa modalidade de viagem.

\section{O Produto Turístico All Inclusive - Todo Incluído (TI)}

Os primeiros indícios do TI datam de 1930, sendo aplicado nos acampamentos de férias Butlin's holiday camps das Ilhas de Barry, pertencentes ao país de Gales. Esses acampamentos foram construídos como alternativa de passeio, durante as férias, de famílias da classe trabalhadora da Grã-Bretanha (POON, 1998; ISSA e JAYAWARDENA, 2003).

Posteriormente, em 1966, as principais operadoras de viagem europeias incluíram e generalizam os programas de férias em destinos mais próximos, como os localizados no litoral mediterrâneo e nas ilhas canárias. Somente em meados de 1970 ocorreu a difusão desse produto em outros países (INSKEEP, 1991), o que contribuiu com a expansão do turismo de massa em diferentes partes do mundo (ANDERSON, 2008; 2009). Desse modo, entre os anos de 1970 e 1980, alguns países como México, a região do Caribe, os destinos africanos e os asiáticos foram pioneiros na inserção dos primeiros resorts All inclusive (CABILDO DE LANZAROTE, 2004).

Vale mencionar que o TI é frequentemente associado a destinos considerados exóticos, sendo vislumbrado como a primeira opção para turistas que desejam viajar com essa motivação. $\mathrm{O}$ crescimento do TI na Alemanha e no Reino Unido, e o sucesso da sua comercialização em destinos como Turquia, Marrocos e Egito, serviram de estímulo para que as operadoras difundissem esse produto nos destinos espanhóis, sobretudo os denominados de "sol e praia", entre eles o arquipélago Canário (NAVARRO; LÓPEZ, 2011).

O TI, como visto, é um produto ou pacote turístico que contempla transporte aéreo (geralmente representado pelas Companhias áreas de baixo custo), hospedagem com serviços de alimentação (restaurante com café da manhã, almoço, lanches, jantar e bebidas), e lazer (atividades de animação e entretenimento). Todos esses serviços são pagos pelo turista no 
período que antecede a viagem (NAVARRO; LÓPEZ, 2011; ALEGRE; POU, 2006; ANDERSON; JUANEDA; SASTRE 2008; ANDERSON, 2009).

É fundamental fazer um paralelo entre a estrutura do TI e outros pacotes, a fim de garantir um melhor entendimento do mesmo. O pacote básico contempla transporte aéreo e hospedagem, já o pacote médio contempla os dois citados e o café da manhã. O pacote TI, por sua vez, abarca todos os serviços mencionados, além de outros como lazer, lanches e bebidas (NAVARRO; LÓPEZ, 2011).

Cabe ressaltar, ainda, que o padrão de qualidade do TI depende de cada hospedagem. Dentre os serviços e atividades distintas que os hotéis oferecem, vislumbram-se várias possibilidades: cuidado das crianças, SPA, cardápio dos restaurantes, atividades fora do hotel, tais como excursões, esportes marítimos e cursos de mergulho. Esses serviços são complementares, sendo acrescentados ao preço do pacote turístico. Diante disso, é importante:

Que el turista conozca que, a pesar del término TI, puede ser que tenga que abonar por servicios no incluidos en el producto adquirido, todos ellos, servicios complementarios que le confieren a este paquete turístico un alto valor añadido. (NAVARRO; LÓPEZ, 2011, p. 250).

Outro aspecto do TI a ser salientado é que muitas vezes essa modalidade é alvo de preconceitos, por ser considerada uma viagem de baixo custo. Essa questão é frequentemente mencionada na literatura sobre o tema (NAVARRO E LÓPEZ, 2011; ALEGRE E POU, 2006; ANDERSON, JUANEDA E SASTRE 2008; ANDERSON, 2009). Porém, há diversas categorias do pacote, desde as básicas até as mais elitizadas, que visam categorizar o TI por meio de diferentes denominações: imperial all-inclusive, ultra all-inclusive, mega all-inclusive e premium allinclusive. Devido ao seu alto custo, esta última é uma das categorias consideradas elitistas.

Os serviços incluídos em cada tipo de pacote TI facilitam a escolha do cliente. Além disso, para otimizar os serviços e atendimento aos turistas, os hotéis disponibilizam uma pulseira como forma de diferenciar a demanda TI dos demais clientes que viajam por outras modalidades ou até mesmo de forma independente. A pulseira varia de cor e de estilo, dependendo de cada hotel. Vale acrescentar, ainda, que os turistas possuem livre acesso aos produtos oferecidos nas dependências dos hotéis, podendo deles usufruir quando e como quiserem, o que evidencia a comodidade que o pacote oferece.

Segundo Alegre e Pou (2006), o TI apresenta vários pontos fortes e fracos. Como principal força tem-se a relação custo-benefício, por serem pacotes diversificados, econômicos e 
acessíveis, facilitam o orçamento do turista. Em contrapartida, a principal fraqueza é o substancial impacto econômico que este tipo de oferta gera nas destinações turísticas. Ou seja, os turistas tendem a ficar reclusos no estabelecimento hoteleiro, o que restringe o seu deslocamento na destinação turística como um todo. Por isso:

Es comúnmente aceptado que este tipo de oferta tiene un impacto sobre la economía de las regiones turísticas. [...] La oferta de Todo Incluido tiene un efecto directo sobre la distribución de los ingresos turísticos en el destino. El porcentaje de gasto que el turista realiza fuera del establecimiento hotelero se ve drásticamente disminuido. Ello debe afectar directamente al sector de restauración, pero no únicamente a éste. Sin duda, la distribución del tiempo de ocio del turista también debe verse afectada, disminuyendo el tiempo y las actividades realizadas en el exterior del establecimiento hotelero. (ALEGRE; POU, 2006, p. 2-6).

Diante de tal cenário, vê-se a complexidade que envolve o produto TI. O quadro 1 expressa de forma mais detalhada as forças e as fraquezas dessa modalidade de viagem.

Quadro 1: Forças e fraquezas do produto Todo Incluido

\begin{tabular}{|c|c|}
\hline FORÇAS & FRAQUEZAS \\
\hline Custo-benefício & $\begin{array}{l}\text { Excessiva animação visando ocupar o máximo de } \\
\text { tempo do turista durante sua estadia. }\end{array}$ \\
\hline $\begin{array}{l}\text { Os turistas podem planejar melhor as férias, } \\
\text { definindo previamente o valor a ser gasto. }\end{array}$ & Escassa tendência de gastar fora do estabelecimento. \\
\hline $\begin{array}{l}\text { Facilidade de comercialização pelas agências de } \\
\text { viagem, que, recebem comissão pelo valor completo } \\
\text { do pacote. }\end{array}$ & $\begin{array}{l}\text { As comissões para os vendedores de pacote Todo } \\
\text { Incluído são mais altas, incentivando sua venda em } \\
\text { detrimento de outros pacotes. (maximização de vendas } \\
\text { do pacote Todo incluído e queda nas vendas de outros } \\
\text { tipos de pacotes turísticos) }\end{array}$ \\
\hline $\begin{array}{l}\text { Simplifica as relações entre o hotel e os hóspedes, } \\
\text { minimizando o investimento necessário para gerir as } \\
\text { faturas dos clientes. }\end{array}$ & $\begin{array}{l}\text { Gastos elevados/investimento em mão de obra } \\
\text { qualificada. }\end{array}$ \\
\hline $\begin{array}{l}\text { s de inventário e estoque, } \\
\text { ação é previamente paga. }\end{array}$ & Én \\
\hline $\begin{array}{l}\text { Elimina a troca de moeda entre o hotel e os } \\
\text { hóspedes. }\end{array}$ & \begin{tabular}{|lrlrr}
$\begin{array}{l}\text { Elimina os } \\
\text { trabalhadores. }\end{array}$ & incentivos & econômicos & para & os \\
\end{tabular} \\
\hline $\begin{array}{l}\text { Os hóspedes não precisam sair do hotel, de maneira } \\
\text { que o valor adicional das atividades complementárias } \\
\text { é capturado pelo hotel. }\end{array}$ & $\begin{array}{l}\text { Pode-se limitar as conexões externas do hotel (por } \\
\text { exemplo: taxis, restaurantes e demais serviços). }\end{array}$ \\
\hline $\begin{array}{l}\text { Os turistas se sentem protegidos em um ambiente } \\
\text { planejado e organizado. }\end{array}$ & $\begin{array}{l}\text { Conduzem a uma experiência turística restrita, ou seja, } \\
\text { limita a participação local e a interação dos turistas } \\
\text { com a comunidade local. }\end{array}$ \\
\hline Pessoal capacitado, qualificado e flexível. & $\begin{array}{l}\text { A equipe de trabalho pode ser facilmente explorada, } \\
\text { alem da sobrecarga de trabalho. }\end{array}$ \\
\hline São necessárias no mínimo 150 habitações. & $\begin{array}{lcccc}\begin{array}{l}\text { Não é muito } \\
\text { estabelecimentos. }\end{array} & \text { apropriado em } & \text { pequenos } \\
\end{array}$ \\
\hline $\begin{array}{l}\text { Introduz outra ca } \\
\text { novos mercados, } \\
\text { para o destino turí }\end{array}$ & $\begin{array}{l}\text { Incapaz de abranger outros tipos de clientes, tais como: } \\
\text { de excursões, de cruzeiros, dentre outros. Como fazem } \\
\text { os hotéis convencionais }\end{array}$ \\
\hline
\end{tabular}

Fonte: (ALEGRE; POU, 2006 apud TOURISM INTELLIGENCE INTERNATIONAL - TII, 2000, p.2). 
Em relação à motivação dos turistas para a aquisição do Todo Incluido, na pesquisa bibliográfica foram identificadas quatro razões principais: a) a relação custo-benefício; b) o conhecimento prévio do gasto total das férias; c) o fato de ser um pacote adequado para o turismo familiar, e d) uma ampla oferta de lazer e entretenimento, contemplada na viagem. (ALEGRE; POU, 2006 apud TOURISM INTELLIGENCE INTERNATIONAL - TII, 2003).

\section{O TI nas Ilhas Canárias e em Tenerife}

As Ilhas Canárias, por apresentarem uma atividade turística bem estruturada, por iniciativa do governo estão constantemente diversificando sua oferta e seus produtos.

Las Islas Canarias son un destino turístico en fase de reorientación, en el que desde todas las instancias del sector, se viene planteando la necesidad de llevar a cabo estrategias de transformación del modelo, complementando y diversificando la oferta. Desde el Gobierno de Canarias se apuesta por "la renovación, la innovación y la regeneración" del espacio turístico, teniendo siempre como norte un turismo de mayor calidad. (NAVARRO; LÓPEZ, 2011, p. 255).

Sendo o TI uma nova tendência de mercado para a região, foi uma das opções de renovação ou até mesmo de inovação da atividade turística no arquipélago canário, de iniciativa do setor privado. De modo geral, as pesquisas oficiais indicam que o TI começou a se expandir em Canárias a partir de 2006, sendo considerada uma oferta recente, porém em pleno crescimento, denotando o seu processo gradativo de inserção nas ilhas (INSTITUTO CANARIO DE ESTADÍSTICA - ISTAC; NAVARRO E LÓPEZ, 2011).

É importante mencionar que neste mesmo ano de 2006, teve início a "crise econômica global atual, assolando diversos países europeus, assim como a Espanha” (MENA, 2009, p.10). Nesse cenário de instabilidade europeu, a eclosão da crise econômica de 2009 foi simultânea à ascensão do Todo Incluido. Embora haja insuficiência de dados em relação ao TI no período 2010-2012, estudos mais recentes desenvolvidos pelo Instituto Canario de Estadística (ISTAC) apontam que cerca de $34 \%$ dos turistas que visitaram as Ilhas Canarias no terceiro trimestre de 2013, o fizeram utilizando o TI, apresentando um aumento de 5,64 pontos, em relação ao ano de 2009.

Embora pareça que a crise financeira da Europa não tenha afetado consideravelmente a economia das ilhas, conforme expõe Matos (2013, s.p.): “El motor económico de Canarias parece que goza de una razonable buena salud a pesar de la profunda crisis económica en la 
que estamos inmersos. Así lo dicen los datos de ocupación turística de los últimos meses y las previsiones de reservas para las próximas temporadas". Há um emaranhado de discussões acerca da incidência do TI nas ilhas Canárias, bem como sobre sua influência na atividade turística. O principal aspecto negativo destacado na literatura (Consejo Económico y Social de Canarias - Ces, 2005; Tourism Intelligence International, 2003; Alegre e Pou, 2006; Navarro e López, 2011; Matos, 2013) refere-se aos danos causados aos empreendedores locais. O CES et al. (2005) destaca que os mais prejudicados são sem dúvida os serviços denominados "oferta complementaria" composto pela alimentação, comércio em geral e as atividades relacionadas ao lazer e entretenimento. Fator este, corroborado por Matos (2013, s.p.):

En este sentido, posiblemente el sector más directamente afectado por esta modalidad de turismo que llena nuestros hoteles pero que tiene un bajo nivel de gasto fuera de las instalaciones de los resorts es sin lugar a dudas el sector comercial del ocio y de la restauración. Lo que se conoce como oferta complementaria.

Segundo Navarro e López (2011), o produto TI foi implantado nas ilhas Canárias por iniciativa das agências e operadoras de viagem. A difusão do pacote nas Ilhas é devida, principalmente, à dependência do transporte aéreo para a chegada de turistas:

El producto turístico canario sigue dependiendo, en un alto porcentaje, de estos agentes intermediarios para su comercialización, debido a la dependencia de un transporte aéreo, y por presentar una lejanía media con respecto a los principales mercados emisores. Ha sido en este tipo de destinos, y aún más en los de larga distancia, donde el TI ha tenido un mayor auge. (NAVARRO; LÓPEZ, 2011, p. 258).

Além disso, por meio da implantação do TI, as agências e operadoras de viagem tinham como objetivo acompanhar as novas tendências do comportamento do turista, bem como posicionar as Ilhas Canarias como destino turístico no mercado competitivo. Em suma, esse tipo de pacote lhes permitiria obter comissões por um valor relativamente alto, devido ao fato do custo com a alimentação e demais atividades estarem incluídas e serem pagas prévia e diretamente às agências. Neste caso, por meio do TI, as agências e operadoras detêm "plenos poderes" sobre o produto.

Portanto, a situação de fragilidade econômica na Europa, somada à dependência aérea, foram dois grandes elementos facilitadores para a adesão da prática no arquipélago Canário como um todo e, particularmente, em Tenerife: "la isla de la eterna primavera".

Tenerife é uma região de expressiva geomorfologia vulcânica, dotada de parques naturais e espaços protegidos, propícios para a prática de inúmeras atividades ecológicas. Um exemplo 
disso, é o Parque Nacional del Teide, que, além de ser considerado pela UNESCO Patrimônio Mundial da Humanidade, sustenta o pico mais alto da Espanha, com 3.718 metros. Dessa forma, Tenerife é considerada umas das regiões mais importantes do arquipélago (CUSCOY, 2003).

A economia das ilhas volta-se basicamente para o turismo. De acordo com o Estudo IMPACTUR Canarias 2012, o turismo canário se manteve como um dos motores do setor turístico espanhol, que representa cerca de $80 \%$ da economia do país. Assim, a ilha conta com uma ampla oferta turística composta por serviços de alimentação e hospedagem, além de inúmeros equipamentos e atrativos, apresentando dessa maneira um mercado turístico bem segmentado e estruturado.

Além disso, Tenerife recebe anualmente uma demanda turística considerável. As pesquisas elaboradas pela prefeitura de Tenerife, como a "Encuesta de Turismo Receptivo", salientam que o período de férias, Natal e, sobretudo o verão, são as ocasiões de maior índice de visitação. Segundo Matos (2013), mesmo diante da crise econômica já mencionada - fator que ocasionou certa queda no índice de visitantes da ilha -, a mesma continua recebendo uma expressiva demanda, contribuindo assim para o pleno funcionamento da sua atividade turística.

Apesar da escassez de dados sobre a incidência do TI em Tenerife, os documentos oficiais elaborados pelo governo fornecem algumas informações. Entre os anos de 2007 a 2011 ocorreu certo aumento na contratação do TI. Dos turistas que visitaram Tenerife em 2011, cerca de $22 \%$ utilizaram o serviço Todo Incluido, obtendo um aumento gradativo em relação aos anos anteriores. Considerando esse crescimento da modalidade, conforme os resultados da enquete desenvolvida pela prefeitura de Tenerife, a contratação prévia do pacote turístico TI no ano de 2012 para realização da viagem lidera com 50,6\% em relação à contratação independente de 49,4\% (ISTAC, 2012).

Pode-se verificar, conforme é apresentado na figura 1, que no ano de 2012 a contratação prévia do pacote Todo Incluido alcançou um percentual de $22,3 \%$ e apresentou um crescimento, enquanto ocorreu um declínio em quase todas as outras modalidades: 


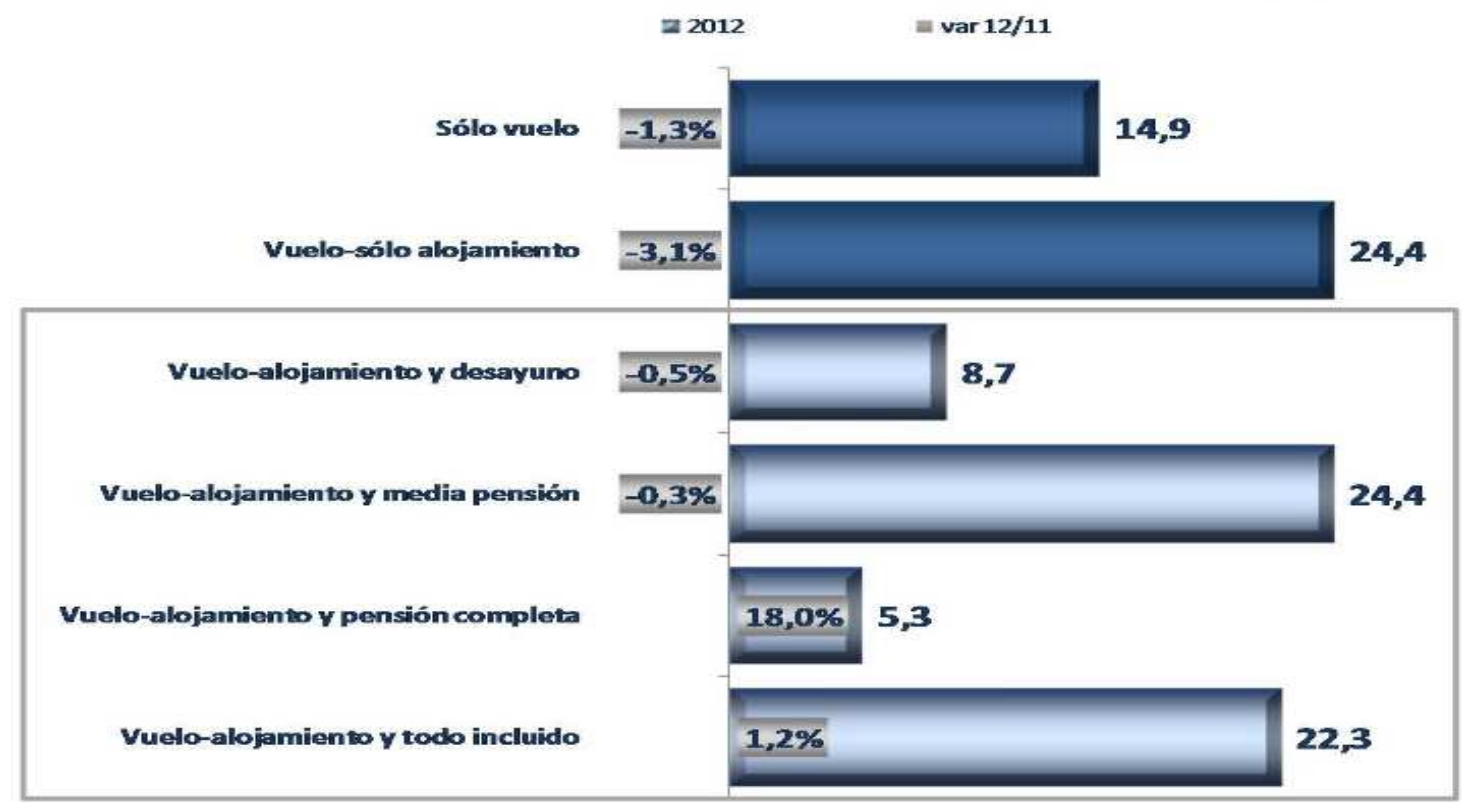

Figura 1: Serviços prévios contratados pelos turistas em 2012

Fonte: Encuesta Turismo Receptivo Cabildo de Tenerife. Disponível em: http://www.webtenerife.com/investigacion/ el-turista-de-tenerife/. Acesso em 20/12/2013.

De acordo com as pesquisas elaboradas pelo Instituto Canario de Estadística (ISTAC), cerca de 32,8\% dos turistas que visitaram Tenerife em 2013, o fizeram utilizando a modalidade TI. Diante de tal cenário, e das informações apresentadas anteriormente, pode-se verificar um aumento de 10,5\% no ano de 2013 da demanda TI da ilha em relação ao ano anterior, com um progressivo avanço ao longo dos anos, como pode ser verificado na figura 2.

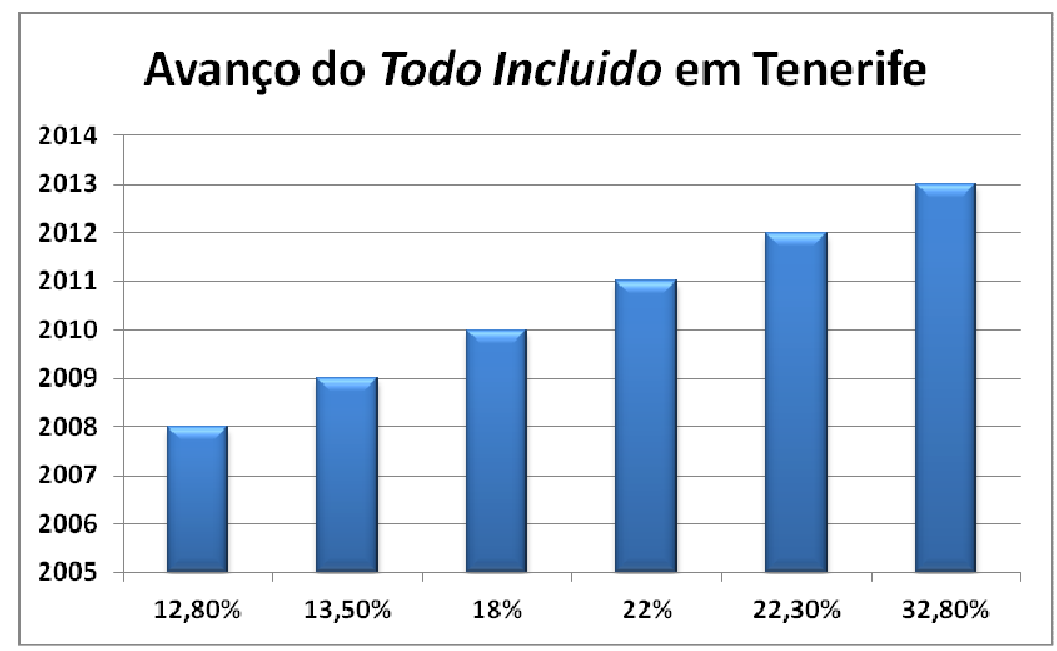

Figura 2: Avanço do TI em Tenerife

Fonte: ISTAC, Encuesta Turismo Receptivo Cabildo de Tenerife e Elaboração própria. 
Em suma, por meio da pesquisa bibliográfica e da análise documental, constatou-se um progresso considerável desse tipo de produto nos últimos anos, sobretudo a partir da crise econômica na Europa e em outros continentes do mundo.

\section{Resultados das Entrevistas}

Como foi salientado na metodologia, as entrevistas foram feitas com 23 turistas, 2 especialistas em Turismo e Hotelaria (que atuaram em Tenerife nesse ramo nos últimos 10 anos) e 2 animadores, totalizando 27 entrevistados. A seleção dos turistas seguiu dois critérios: (a) ser turista hospedado na modalidade TI e (b) estar hospedado por um período igual ou superior a uma semana, tempo este considerado suficiente para, se fosse o caso, ter realizado atividades turísticas externas ao estabelecimento hoteleiro. Foram também entrevistados 2 animadores (um de cada hotel), e 2 especialistas em Turismo e Hotelaria, totalizando assim, 27 pessoas.

Foi possível constatar, entre os turistas, um predomínio de pessoas oriundas de Madri, Espanha (10 pessoas), seguido da Inglaterra com 7, e Alemanha com 6 turistas entrevistados. Em relação ao sexo, nesse grupo foram 12 homens e 11 mulheres.

A faixa etária é diversificada, variando entre 40 a 70 anos. Grande parte dos entrevistados estava viajando em família, com exceção de três pessoas que alegaram viajar sozinhos. Prevaleceu o estado civil casado e todos os entrevistados têm filhos.

Em relação ao produto TI, os 23 turistas entrevistados permaneceram duas semanas hospedados nos hotéis. Quanto aos fatores que motivaram a contratação desse produto turístico, em primeiro lugar foi enfatizado o preço do pacote (valor total pago antecipadamente, conhecimento prévio do custo total das férias). Em segundo lugar, os benefícios do produto, que apresenta todos os serviços incluídos - transporte ao destino, alimentação, hospedagem, lazer e entretenimento - considerados necessários para propiciar um agradável período de férias.

Tendo em vista as possíveis vantagens do pacote TI, foi constatada uma unanimidade em relação ao preço, o que é também um fator de motivação para a compra do pacote. Portanto, as entrevistas confirmaram os dados já encontrados na literatura: preço, comodidade e 
serviços oferecidos são as principais motivações em relação ao produto. De modo geral, o pacote representa para os turistas entrevistados o tripé tranquilidade, lazer e liberdade.

Como desvantagens, 20 dos 23 turistas afirmaram que se sentem enclausurados. Porém, relataram que sair do hotel pode acarretar gastos extras, não previstos no planejamento da viagem. Além disso, sair do hotel significa perda de algum serviço e, consequentemente, desperdício de dinheiro.

Durante a realização das entrevistas nos hotéis, os animadores expuseram quais atividades eram ofertadas para os turistas no decorrer do dia. Além de alimentos e bebidas diversas, incluindo alcoólicas, há uma gama de atividades de lazer e entretenimento, algumas similares, porém outras são peculiares de cada hotel, como é possível verificar no quadro 2 .

Quadro 2: Atividades ofertadas nos hotéis

\begin{tabular}{|l|l|}
\hline \multicolumn{1}{|c|}{ Hotel I } & \multicolumn{1}{|c|}{ Hotel II } \\
\hline Spa & Sinuca, Totó \\
\hline Campo de Mini-golf & Bingo \\
\hline $\begin{array}{l}\text { Shows: contorcionistas, mágica, dança do ventre, } \\
\text { comédia, músicos e bandas locais, festas temáticas } \\
\text { (eventos tanto para público adulto quanto o infantil). }\end{array}$ & $\begin{array}{l}\text { Shows: contorcionistas, mágica, dança do ventre, } \\
\text { comédia, músicos e bandas locais, (eventos tanto para } \\
\text { público adulto quanto o infantil). }\end{array}$ \\
\hline Academia & Desfiles de moda praia verão \\
\hline Atividades e brincadeiras na piscina & Atividades e brincadeiras na piscina \\
\hline
\end{tabular}

Fonte: Elaboração própria.

Esse resultado evidencia as distintas atividades de entretenimento que são oferecidas aos hóspedes, e tais serviços são distribuídos ao longo da semana.

Foram entrevistados também dois especialistas em Turismo e Hotelaria que atuavam na gerência de hotéis em Tenerife. Um deles é do sexo masculino e tem 55 anos. Oriundo de Madri vive há 40 anos na Ilha, e trabalhava há 12 anos com gerência de hotel. A outra especialista é do sexo feminino e tem 45 anos. Nascida na Inglaterra, reside na Ilha há 25 anos e atua há 10 anos no ramo hoteleiro.

\subsection{O TI em Tenerife: Perspectivas dos entrevistados}

A concentração de pessoas no hotel pode ser responsável, ao menos parcialmente, pela queda no índice de visitação de outros empreendimentos locais de Tenerife. Isso pode ser devido a distintos fatores, dentre eles o aumento da demanda TI na ilha. Tal perspectiva foi destacada pelos especialistas em turismo: 
Creo que el paquete TI concentra toda la gente y la renta de un destino en los hoteles, y a mí me parece que quieren ganar por medio de la crisis, a mí me parece una alternativa a la crisis, y por eso se están desarrollando cada vez más el todo incluido y cuanto más concentran la gente en los hoteles mas grande es la ruptura en los servicios locales. (EETH1).

Mi perspectiva es que el paquete TI, ha venido debido la crisis, y el turismo fue la manera para que la economía de España no sufra tanto con los reflejos, y como no hay un controle, los servicios y atractivos locales están en desventajas. (EETH2).

Esses relatos evidenciam o impacto do TI na economia de um destino turístico, devido à concentração da demanda nos hotéis, culminando na escassa tendência dos turistas gastarem fora do estabelecimento. Esse fator, obviamente, pode gerar a quebra dos demais empreendimentos e atrativos da localidade (ALEGRE; POU, 2006; CES, 2005).

A visão dos especialistas se assemelha às ponderações encontradas na pesquisa bibliográfica sobre a inserção da modalidade TI em uma região, ser devido também a crises econômicas, podendo ser um meio para enfrentá-las (NAVARRO; LÓPEZ, 2011).

Esse foi o posicionamento do especialista (EETH2), ao salientar que o papel do turismo atrelado ao pacote TI, é uma alternativa para driblar os reflexos da crise na economia. Essa percepção reforça o ideário do turismo, apresentado por Gonçalves (2002), como uma atividade econômica compensatória para muitos governantes, que favorece a resolução de problemas econômicos. Dessa forma, muitas vezes o turismo é visto como uma "panaceia", ou como "a cura para todos os males" encarregado de minimizar ou até erradicar os problemas decorrentes de vulnerabilidades financeiras. Posicionamento este que, apesar de ser plausível, não pode ser tratado como uma verdade absoluta devido a toda a complexidade que permeia a cadeia produtiva do turismo (GONÇALVES, 2002).

Os animadores entrevistados acreditam que há certa satisfação dos turistas no que concerne aos benefícios do pacote, sobretudo em relação à comodidade que o produto TI oferece aos turistas.

[...] el TI es una estrategia, para llenar los hoteles, ya que ofrecen muchos servicios y comodidad como ventaja para los turistas. Por eso creo yo que los clientes están cada vez más en busca de comodidad y descanso, por eso compran el paquete. (ETA1).

Llevo mucho tiempo trabajando con animación y en los últimos 3 años veo que el cliente que estamos recibiendo quiere cada vez más comodidad, comer, beber, jugar y eso, no hacer nada más, sino descansar. Además es creciente el cliente mayor que estamos a recibir, esto puede justificar la busca por descanso. (ETA2). 
Além disso, de acordo com a colocação acima (animador ETA2), nos últimos três anos verifica-se um crescimento da busca por conforto e comodidade. Isso impulsionou consideravelmente o TI na ilha, conforme os dados expressos nos estudos desenvolvidos pelo ISTAC (2013) e na Encuesta Turismo Receptivo (2012) da prefeitura de Tenerife. Outro aspecto mencionado pelo mesmo depoente é em relação ao aumento da demanda da "terceira idade", um público que vem aumentando desde o ano de 2012.

A partir do relato dos dois animadores, é possível traçar um paralelo com as ideias de Krippendorf (2011). Segundo o autor a viagem vem funcionando como uma forma de fugir da rotina, isto é, escapismo. A necessidade de viajar "a qualquer preço" na busca por lazer e descanso, para renovar as energias, é um alento que permite o retorno ao cotidiano maçante, no qual essa necessidade perpassa o imaginário da atual sociedade industrial em relação à viagem.

Sob esse prisma, alguns turistas salientaram os motivos de sua satisfação em relação ao TI durante suas férias:

Me gusta la comodidad y descanso ofertada por el paquete, además del precio, no tengo preocupaciones con dinero ni nada, es todo muy sencillo, hay que disfrutar de esta tranquilidad. (ETI1).

Con tantas ofertas dentro del complejo, se te hace muy perezoso salir. (ETI5).

Tais depoimentos ratificam a tendência, cada vez maior, do turismo concentrar-se nos hotéis. A gama de serviços neles ofertados, designada de "excessiva animação e buffet/restaurante", (ALEGRE; POU, 2006 apud TII, 2003), entra em consonância com a ideia do lazer como mero produto a ser comercializado e consumido, criado neste contexto para a ocupação do tempo livre dos turistas, de forma massificada. Processo este, fruto de um sistema capitalista que propiciou a estandartização e mercantilização do lazer.

No que concerne à permanência dos clientes nos meios de hospedagem, os turistas ressaltaram os motivos pelos quais não querem ausentar-se do hotel:

Pues no tengo ganas de salir del hotel, aunque sepa que hay muchas bellezas a conocer, es más cómodo quedarme en el hotel. (ETI7).

You have everything in the hotel. (ETI14).

Como pode-se constatar, a visão dos entrevistados se complementam, legitimando as considerações tecidas anteriormente. É importante destacar que, apesar da maioria dos 
depoentes relatar a liberdade que o pacote oferece, muitas vezes o turista se sente obrigado a permanecer nas dependências do hotel:

Its obligates you to stay at hotel all day long. So I don't move away from the hotel. (ETI8).

Dessa forma, verifica-se certo paradoxo: ao mesmo tempo em que os depoentes consideram que o TI proporciona liberdade, permitindo-lhes livre acesso às dependências e serviços do hotel, a lógica desse produto acaba "obrigando-os" a permanecer reclusos, sendo, portanto, uma liberdade repleta de contradições. Dessa forma, a ausência de interlocução com a cultura local leva à condição de "isolamento" proporcionada pelos espaços denominados "não lugares". Sob este parâmetro, Augé (2012) adverte que os "não lugares" geram perda de identidade nos indivíduos, já que este espaço "cria solidão e similitude" (p.95) em detrimento da "liberdade e deslocamento" (p.78), no destino escolhido para viajar.

É essencial pontuar os limites que o turismo acaba tendo quando a proposta prevê um "enclausuramento" dos turistas. Sob esta perspectiva, Baudelaire (s/a, p. 52-53) defende que a "rua" deve ser vivida, experimentada e observada, pois, ela "representa a liberdade em oposição ao enclausuramento". Essa perspectiva de liberdade não foi notada na pesquisa, uma vez que as interações do turista com a cultura local foram praticamente inexistentes e destituídas de experiências de viagem enriquecedoras no destino turístico escolhido para além das delimitações do meio de hospedagem TI.

Gastal e Moesch (2007) acreditam que o turismo sob a perspectiva de deslocamento e mobilização dos indivíduos, deve ser compreendido como uma experiência para os sujeitos, no sentido de se defrontarem com o desconhecido, o inesperado, e a possibilidade de vivenciar uma nova realidade. Dessa forma, uma vivência turística cultural tem a capacidade de transformar a viagem dos sujeitos em uma experiência de descoberta, trocas culturais, conhecimento e enriquecimento pessoal. Gastal e Moesch (2007) ressaltam que:

Os processos de mobilização subjetiva que o levariam a parar e a re-olhar, a repensar, a reavaliar, a ressignificar não só a situação, o ambiente, as práticas vivenciadas naquele momento e naquele lugar, mas muitas das suas experiências passadas (p.10).

As autoras enfatizam, ainda, que uma "concepção mais contemporânea e articuladora de vivências locais e globais entre cidadãos e visitantes, entre fluxos e fixos, [resistiria] a uma produção espetacularizada, artificial, só para turistas" (p. 46). 
Ainda com relação à permanência exclusiva no meio de hospedagem, alguns depoentes mencionaram sentir vergonha de sair do hotel com a pulseira do Todo Incluido, o que está relacionado com as seguintes razões:

(a) Pelo fato da pulseira ser de papel (The bracellet is paper, and ugly. ETI19).

(b) A pulseira não poder ser retirada, pois muitos hotéis não disponibilizam outra (Necesitamos estar con la pulsera todo el tiempo para ter acceso a los servicios, y creo que el hotel no dame otra, así que no puedo quitármela. ETI15).

(c) Por representar a única identificação de fato que o diferencia dentro do hotel, dos demais hóspedes que não são turistas TI (La pulsera es la única manera de que sepan que soy del paquete TI, y puedo consumir los servicios con libertad y tranquilidad - ETI16; Son muchos turistas, la pulsera sirve para diferenciar los clientes TI de los clientes normales - EA2).

(d) Por evidenciar que a pessoa está viajando de TI (Nadie necesita saber que viajo de TI. Me da vergüenza, es un viaje de bajo costo - ETI18; El todo incluido a menudo es asociado a viajes de bajo costo, pero con la evolución del fenómeno hay distintos tipos de TI de alta e baja categoría y costo - EETH1).

É possível constatar, assim, que o TI em Tenerife carrega o estigma depreciativo de ser uma viagem de baixo custo. Embora o entrevistado (ETI18) alegue ter vergonha de mostrar que está realizando uma viagem de baixo custo, é válido relembrar, conforme expõe o especialista (EETH1), a existência de diferentes tipos de pacotes TI, que muitas vezes podem envolver um alto custo. Dessa forma, o TI em muitos destinos apresenta um padrão de luxo, atingindo também clientes elitistas, que querem desfrutar de férias luxuosas (NAVARRO; LÓPEZ, 2011).

O consenso por parte da maioria dos entrevistados em relação à disposição de não efetuar gastos durante a hospedagem no sistema TI pode ser explicado, sobretudo, pela própria concepção do pacote. Afinal, no momento de contratar o pacote, o turista fica ciente do custo total das férias, não sendo necessário realizar gastos inesperados.

Tal perspectiva também foi salientada pelos animadores que trabalham nos hotéis:

Veo que los clientes conocen cada vez menos la isla, no les gusta salir, pues ya está todo incluido en el paquete, y les da miedo perder algún servicio o actividad dentro del hotel, pues pagaron. (EA1).

Los clientes no quieren salir, no quieren gastar un valor a más de lo paquete que ya habían contratado en su país. (EA2). 
Assim, os turistas acabam evitando gastar mais dinheiro, além do que já foi pago previamente:

No tengo ganas de salir ni tan poco gastar afuera del hotel, he pagado por el servicio antes del viaje, además, es un sitio increíble. (ETI9).

I can eat like a pig, and not spending more money. (ETI12).

Sob essa mesma lógica, embora muitos entrevistados não tenham manifestado motivação para sair dos hotéis, para não contrair novas despesas, há aqueles que têm interesse e pretendem conhecer outros empreendimentos externos. Dessa maneira os turistas que almejavam sair do hotel estavam motivados em conhecer outros lugares:

I'll go to the Teide vulcano, Loro park, Siam Park and the capital of this island. (ETI23).

Excursiones por toda la isla, parque Teide, Loro Park, Siam Park y me gustaría descubrir nuevos paisajes y entornos. (ETI22).

Há que se ressaltar, também, a ausência de um planejamento turístico, ou até mesmo de certo controle de caráter público acerca do desenvolvimento do TI na ilha, uma vez que o mesmo é regido pelo poder privado, evidenciando certa desigualdade nos ganhos derivados do Todo Incluido, conforme expõem os especialistas:

Creo yo que el Todo Incluido carece de un control por parte del gobierno, junto al sector privado, necesita un control, para que no sea tan impactante, donde muchos están perdiendo y pocos ganan. (EETH1).

El paquete Todo incluido necesita de ordenación, para disminuir la desigualdad, el TI necesita ser desarrollado igualmente, hay mucha renta concentrada en solamente un espacio, las agencias, los hoteles y las compañías aéreas son los que tienen más ventaja sobre la venta del paquete. (EETH2).

Além do que foi destacado anteriormente, conforme relatam os entrevistados abaixo, há muita concorrência por parte da rede hoteleira em relação aos outros serviços e equipamentos turísticos. Fator este que acaba por reforçar a concentração do lucro, bem como a desarticulação entre os hotéis com os demais empreendimentos locais:

Los hoteles no actúan en cadenas, hay mucha competencia entre los complejos hoteleros así hay competencia con los restaurantes y otros servicios del turismo. (EETH1).

Hay mucha competencia entre los hoteles y con los otros emprendimientos locales. (EA2).

Considerando esses resultados, ressalta-se a importância da criação de políticas públicas de turismo que possam contribuir para o processo de regulamentação do produto TI em Tenerife. 
Uma política pública de turismo pode ser entendida "como um conjunto de intenções, diretrizes e estratégias estabelecidas e/ou ações deliberadas, no âmbito do poder público, em virtude do objetivo geral de alcançar e/ou dar continuidade ao pleno desenvolvimento da atividade turística num dado território." (CRUZ, 2000, p. 40).

Tendo em vista que o TI de Tenerife é regido, sobretudo, pelo setor privado, é fundamental criar ações e estratégias governamentais que promovam o desenvolvimento desse produto turístico de forma sinérgica intersetorial, ou seja, contemplando o setor público e o privado. Segundo Cruz (2000), essa seria a única forma de reduzir os possíveis efeitos negativos da atividade turística e concomitante a isso aumentar os efeitos positivos. A autora enfatiza que o planejamento e a política pública comprometida com os interesses da coletividade, são mecanismos cruciais para gerar benefícios na atividade turística.

\section{Considerações Finais}

Esta pesquisa permitiu compreender que, atualmente, o TI se configura nas Ilhas Canárias, especialmente em Tenerife, como um produto turístico que continua em pleno crescimento e expansão. Embora conte com apoio governamental, vem sendo regido pelo poder privado e marcado por ambiguidades e inúmeros desafios.

Isso é decorrente, entre outros fatores, do TI ter sido concebido no seio das relações econômicas sob um contexto de fragilidade financeira na Europa e em outras partes do mundo. O TI consiste, dessa maneira, na reformulação do mercado interno da região, sendo caracterizado pela (re)adaptação, renovação e ampliação da oferta de novos mercados, influenciado direta e indiretamente pela demanda.

Foi possível verificar que os turistas que consomem esse produto turístico são, predominantemente, um público familiar que está em busca de descanso e refúgio, sobretudo durante o período de férias. O TI é apreendido pelos turistas como um produto que proporciona tranquilidade, lazer, liberdade e comodidade a um preço acessível - constituindo, dessa forma, um pacote atrativo e vantajoso.

Quase todos os turistas explicitaram que não tinham pretensão de sair do hotel: preferiam descansar e evitar gastos extras, uma vez que o empreendimento já oferecia todo o necessário para desfrutar as férias. Por meio das entrevistas e também da análise documental foi possível 
constatar, assim, que os turistas que adquirem o TI não têm motivação para visitar outros atrativos turísticos de Tenerife por diversas razões, entre as quais se destacam a diversificada oferta de atividades e serviços nos hotéis e a necessidade de consumir o que foi pago previamente e a comodidade.

Observou-se, ainda, que o TI em Tenerife carece de estruturação política. Assim sendo, é imprescindível ressaltar a importância que as políticas públicas de turismo podem proporcionar a um dado destino, no sentido de co-contribuir para o planejamento e gestão da atividade turística de forma mais igualitária, e até mesmo identitárias.

Conforme afirmam Gastal e Moesch (2007, p. 49): “deve haver uma gestão turística que identifique, mobilize e arregimente os agentes institucionais e atores sociais, as lideranças comunitárias, políticas e empresariais da região." As autoras pontuam, ainda, que as políticas públicas de comunicação têm o poder de reforçar a venda de pacotes turísticos estereotipados, no qual os desejos acabam tornando-se homogeneizantes, culminando no distanciamento do turista com a localidade para a qual viaja. Dessa forma, defendem a necessidade de "priorizar a concepção de um turismo sustentável e humano [...], o qual se distancia do turismo de massa, impactante e ilusório [...].” (p.46).

Devido ao fato da temática aqui abordada ser incipiente, vê-se a relevância de dar continuidade a investigações aprofundadas e crítico-reflexivas, na tentativa de ampliar os estudos e discussões do lazer e turismo sob essa perspectiva. Afinal, o turismo requer não somente políticas públicas encarregadas de preparar os destinos para receber visitantes, demandando também políticas públicas que garantam a todos os segmentos sociais, o exercício e o usufruto do lazer e do turismo (GASTAL; MOESH, 2007).

Por fim, a gestão e o planejamento socioparticipativos - elaborados por meio de políticas públicas de turismo - poderão colaborar para regularização do TI. Dessa maneira, pode-se reduzir a desigualdade social vigente em Tenerife e em outros contextos. Pois, é neste quadro de disparidade socioeconômica - dos lucros provenientes do produto TI -, que se encontram muitos dos serviços, equipamentos e atrativos turísticos da região.

\section{Referências}

ALEGRE, J. e POU, L. El Paquete Turístico de Todo Incluido: Un análisis de sus implicaciones económicas para el caso de las islas baleares. Universitat de les Illes Balears: Departamento de Economía Aplicada, 2006. 
ANDERSON, W. Determinants of all-inclusive travel expenditure. Govern de les Illes Balears: Conselleria d'Economia Hisenda Innovacio, 2009.

ANDERSON, W., Juaneda, C., e Sastre, F. Influences of pro- all-inclusive travel decisions. Govern de les Illes Balears: Conselleriad'Economia Hisenda innovacio, 2008.

AUGÉ, M. Não lugares: Introdução a uma antropologia da supermodernidade. Campinas: Papirus, 2012.

AUGUSTA, L. S. A importância do planejamento governamental do turismo: O prodetur na Bahia. Bahia Análise \& Dados Salvador, vol.2, n.12, 101-114, 2002.

BAUDELAIRE, C. As Multidões. In: Arabescos Filosóficos. Rio de Janeiro: Casa Editora Vecchi Ltda, s/d.

CABILDO DE LANZAROTE, Informe sobre el todo-incluido en Lanzarote. Centro de Datos: Consejería de Ciencia y Tecnología, 2004.2 Disponível em: <http://www.datosdelanzarote.com/Uploads/doc/-Todo-Inclu\%C3\%ADdo-en-Lanzarote-

2013061714155929620060606121709922InformeTODOINCLUIDO.pdf> Acesso em: 10 nov. 2013.

CRUZ, R. Política de turismo e território. São Paulo: Contexto, 2000.

CUSCOY, D. Tenerife, la isla del Teide. Santa Cruz de Tenerife: Idea, 2003.

Dictamen el Consejo Económico y Social de Canarias - CES La incidencia del Todo Incluido en Canarias, 2005.20 Disponível <http://www.cescanarias.org/publicaciones/dictamenes/dic_4_2005.pdf.> Acesso em: 17 Dez. 2013

Encuesta Turismo Receptivo, 2012. Disponível em: < http://www.webtenerife. com/investigacion/elturista-de-tenerife/> Acesso em: $20 \mathrm{dez}, 2013$.

Excel Tur e Gobierno de Canarias Impactur Canarias: Estudio del impacto económico del turismo sobre la economía y el empleo de las islas canaria, 2012. Disponível em: <http://www.gobcan.es/opencms8/opencms/presidencia/turismo/downl oads/Impactur/IMPACTUR_Canarias_2012.pdf> Acesso em: 17 Nov. 2013.

FUNARI, P., e Pinsky, J. Turismo e patrimônio cultural (orgs). São Paulo: Contexto, 2003.

GASTAL, S., e Moesch, M. Turismo, políticas públicas e cidadania. São Paulo: Aleph, 2007.

GARCIA A. La Planificación de Centros Turísticos. México: Limusa, 1998.

INSKEEP, E. Tourism Planning: An Integrated and Sustainable Development Approach. New York: John Wiley, 1991.

ISTAC - Instituto Canario de Estadística. Todo Incluido, 2012; 2013. Disponível em: <http://www.gobiernodecanarias.org/istac/.content/noticias/ISTACnoticia_100148.html> . Acesso em: 15 Dez. 2013.

ISSA, J. e JAYAWARDENA, C. The All-inclusive concept in the Caribbean. International Journal of Contemporary Hospitality Management, vol. 3, n 15, 167-171, 2003.

IGNARRA, R. Fundamentos do turismo. São Paulo: Pioneira, 1998.

KRIPPENDORF, J. Sociologia do Turismo: Para uma nova compreensão do lazer e das viagens. São Paulo: Aleph, 2001.

MATOS, G. El Todo Incluido en el comercio en Canarias, 2013. Disponível em: < http://www.diariodeavisos.com/2013/10/todo-incluido-en-comercio-en-canarias-por-gustavo-matos/> Acesso em: 16 Dez. 2013.

MOESCH, M. A produção do saber turístico. São Paulo: Contexto, 2000. 
NAVARRO, M. e LÓPEZ, E. El Todo Incluido en Canarias, 2011. Disponível em:< http://www.think-atl.es/wp-content/uploads/group-documents/13/13649 turismo_en_canarias.pdf > Acesso em: 10 de Nov. 2013.

POON, A. All-inclusive resorts Economic Intelligence Unit, Travel and Tourism Analyst, 1998. Disponível em: <http://citeseerx.ist.psu.edu/showciting?cid=37375935> Acesso em: 9 de Nov. 2013.

SANTANA, A. La antropología y el turismo. Barcelona: Ariel, 1997.

SANTOS, R. Metodologia Científica: A construção do conhecimento. Rio de Janeiro: DP\&A, 2000.

THIRY C. Saturação em Pesquisa Qualitativa: Estimativa empírica de dimensionamento; 2006. Disponível em: <http://www.revistapmkt.com.br/Portals/9/Edicoes/Revista_PMKT_003_02.pdf > Acesso em: 10 de Nov. 2013.

\section{Sites consultados}

$<$ http://www.turismodecanarias.com/islas-canarias-espana/viajes-de-vacaciones/lugares-de-interesimprescindibles/isla-tenerife/parque-nacional-del-teide/index.html.> Acesso em 16 nov. 2013.

<http://www.gobiernodecanarias.org/turismo/.> Acesso em 14 fev. 2014.

<http://www.turismodecanarias.com/Ilhas-Can\%C3\%A1rias-espanha/.> Acesso em 15 jan. 2014.

<http://whc.unesco.org/en/list/1258.> Acesso em 16 nov. 2013.

<http://www.webtenerife.com/investigacion/.> Acesso em 20 dez. 2013.

\section{Recebido em: 06/01/2016}

Aprovado em: 12/04/2016 